\title{
Composição química do feijão caupi (Vigna unguiculata L. Walp), cultivar BRS-Milênio
}

\author{
Chemical composition of cowpea (Vigna unguiculata L. Walp), BRS-Milênio cultivar
}

\author{
Karoline de Macêdo Gonçalves FROTA ${ }^{1}$, Rosana Aparecida Manólio SOARES ${ }^{1}$, José Alfredo Gomes ARÊAS ${ }^{1 \star}$
}

\begin{abstract}
Resumo
O feijão caupi é uma das principais culturas alimentares do Nordeste brasileiro. Para melhorar sua resistência contra pragas e produtividade, a nova cultivar (BRS-Milênio) foi obtida por melhoramento genético. Este trabalho objetivou caracterizar o potencial nutricional desta variedade, determinando-se a composição centesimal, o perfil de aminoácidos e ácidos graxos, o conteúdo de minerais e a atividade inibitória de tripsina. A semente contém (g.100 $\mathrm{g}^{-1}$ ): 24,5 de proteínas; 51,4 de carboidratos; 16,6 de fibra insolúvel e 2,7 de fibra solúvel; 2,6 de cinzas, tendo como principais minerais (mg.100 $\mathrm{g}^{-1}$ ): ferro - 6,8; zinco - 4,1; manganês - 1,5; fósforo - 510,0 e potássio - 1430,0. O teor de lipídios foi de 2,2\%, e seu perfil de ácidos graxos apresenta $29,4 \%$ de saturados e $70,7 \%$ de insaturados. Foi estimado valor calórico de $323,4 \mathrm{kcal} 100 \mathrm{~g}^{-1}$ de semente. Encontrou-se baixa atividade inibitória de tripsina (8,0 UIT.mg ${ }^{-1}$ de amostra). O perfil de aminoácidos foi favorável ao padrão de referência, exceto pela deficiência de sulfurados, sugerindo a necessidade da combinação desta leguminosa com outras fontes alimentares. Os resultados indicam que o feijão caupi possui atributos desejáveis como altos teores de energia, proteínas, fibras e minerais, baixa atividade inibitória de tripsina e, apesar de reduzido conteúdo lipídico, contém alta proporção de ácidos graxos insaturados.
\end{abstract}

Palavras-chave: feijão caupi; composição centesimal; perfil de aminoácidos; perfil de ácidos graxos; inibidor de tripsina; teor de minerais.

\begin{abstract}
Cowpea is one of the major food cultures of the northeastern region of Brazil. To improve its resistance against plagues and to increase its productivity, a new cultivar (BRS-Milênio) was obtained by genetic improvement. This study aimed at determining the proximate composition, amino acid and fatty acid profiles, mineral constituents and trypsin inhibitory activity of this cultivar. The seed presents $\left(\mathrm{g}^{1} 100 \mathrm{~g}^{-1}\right): 24.5$ protein, 51.4 carbohydrates, 16.6 insoluble fiber and 2.7 soluble fiber, 2.6 ash; major mineral constituents (mg. $\left.100 \mathrm{~g}^{-1}\right)$ were: iron - 6.8, zinc - 4.1, manganese - 1.5, phosphorus - 510.0 and potassium - 1430.0. Lipid content was $2.2 \%$, and its fatty acids profile: $29.4 \%$ saturated and $70.7 \%$ unsaturated. The caloric value was estimated as $323.4 \mathrm{kcal} .100 \mathrm{~g}^{-1}$ of seeds. A low trypsin inhibitory activity was found (8.0 TIU.mg ${ }^{-1}$ of sample). The amino acid profile is in accordance with the reference amino acid standard, except for the sulfur amino acid deficiency, suggesting the need to encourage the combination of this bean with other food sources. Results suggest that cowpea presents high contents of energy, protein, dietary fiber, minerals and a low trypsin inhibitory activity. Although it contains low amounts of lipids, its composition presents a high unsaturated fatty acid profile.

Keywords: cowpea; proximate composition; amino acid content; fatty acids profile; trypsin inhibitors; minerals.
\end{abstract}

\section{Introdução}

O feijão caupi (Vigna unguiculata L. Walp.), comumente chamado de feijão de corda ou feijão macassar, é um alimento básico para as populações de baixa renda do Nordeste brasileiro. Constitui-se uma das principais culturas alimentares desta região e também do Oeste da África (ONWULIRI; OBU, 2002). Dentre os diferentes produtos agrícolas encontrados nas regiões tropicais, o caupi se destaca pelo alto valor nutritivo, além do baixo custo de produção. É amplamente cultivado pelos pequenos produtores, constituindo um dos principais componentes da dieta alimentar, especialmente na zona rural (EMBRAPA MEIO NORTE, 2003).

Em termos mundiais, a área ocupada com feijão caupi é de cerca de 12,5 milhões de ha, com 8 milhões (64\% da área mundial) na parte oeste e central da África e o restante nas
Américas do Sul e Central, e na Ásia. Os principais produtores mundiais são Nigéria, Niger e Brasil (QUIN, 1997).

No Brasil, o feijão caupi é cultivado predominantemente no sertão semi-árido da região Nordeste e em pequenas áreas na Amazônia (MAIA, 1996). No Nordeste, a produção e a produtividade são de 429.375 toneladas e $303,5 \mathrm{~kg}$ ha $^{-1}$, respectivamente. Os maiores produtores são os Estados do Ceará, Piauí, Bahia e Maranhão, os quais também apresentam as maiores áreas plantadas (IBGE, 2001). A produção dos grãos, secos ou verdes, é destinada principalmente para o consumo humano in natura, na forma de conserva ou desidratado (EMBRAPA MEIO NORTE, 2003).

Esta leguminosa constitui importante fonte de proteínas (23 a $25 \%$ em média) e carboidratos, destacando-se pelo alto

Recebido para publicação em 30/5/2007

Aceito para publicação em 22/8/2007 (002565)

Departamento de Nutrição, Faculdade de Saúde Pública, Universidade de São Paulo - USP, Av. Dr. Arnaldo, 715, CEP 01246-904, São Paulo - SP, Brasil,

E-mail: jagareas@usp.br

${ }^{*}$ A quem a correspondência deve ser enviada 
teor de fibras alimentares, vitaminas e minerais, além de possuir baixa quantidade de lipídios que, em média, é de 2\% (EMBRAPA MEIO NORTE, 2003).

A qualidade nutricional das proteínas das leguminosas é influenciada pelo gênero, espécie, variedade botânica, concentração de fatores antinutricionais, tempo de estocagem, tratamento térmico e, em geral, é inferior àquela da proteína de origem animal (BRESSANI, 1993; CRUZ et al., 2003). No entanto, o alto custo da proteína animal faz com que as proteínas vegetais sejam o principal componente da dieta de diversas populações (IQBAL et al., 2006). Na dieta, o feijão além de aumentar a quantidade de proteínas também contribui para melhorar sua qualidade, quando a fonte protéica da dieta é constituída de leguminosas e cereais. Isto porque enquanto as leguminosas apresentam deficiência em aminoácidos sulfurados, os cereais apresentam deficiência em lisina (IQBAL; KHALIL; SHAH, 2003).

O feijão caupi, como a maioria das sementes de leguminosas, requer tratamento térmico antes do seu consumo, a fim de inativar fatores antinutricionais como inibidores de amilases e lectinas e também melhorar a digestibilidade da proteína e a sua palatabilidade (MENCION; VAN DER POEL, 1993; LIENER, 1994; LALLES; JANSMAN, 1998; CARBONARO et al., 2000).

Estudos bioquímicos de sementes de plantas domesticadas e a produção contínua de novas cultivares obtidas através de técnicas de melhoramento genético têm demonstrado importantes mudanças na composição química das sementes e mesmo na expressão de proteínas envolvidas na defesa da planta (CHRISPEELS; RAIKHEL, 1991).

As pesquisas da Embrapa Meio Norte e da Embrapa Amazônia Oriental culminaram no lançamento da cultivar BRS-Milênio, obtida por melhoramento genético. Esta apresenta melhores características agronômicas, como maior produtividade (mais de 25\%) quando comparada à média regional das demais cultivares e uniformidade da produção. O benefício começa no campo e se estende até o comércio para consumo, pois a produção mais uniforme deixa o produto final com qualidade e apresentação melhores (EMBRAPA AMAZÔNIA ORIENTAL, 2005). No entanto, não se pode deixar de levar em consideração que a melhoria das características agronômicas deve vir acompanhada de melhorias nos parâmetros nutricionais ou que estas sejam pelo menos equiparáveis às características do grão originário.

Neste estudo, portanto, buscou-se conhecer os aspectos bioquímicos e nutricionais desta nova cultivar de feijão caupi (BRS-Milênio), incluindo a composição centesimal, o perfil de aminoácidos e de ácidos graxos, o conteúdo de minerais e a atividade inibitória de tripsina.

\section{Material e métodos}

\subsection{Material}

A amostra de feijão caupi (Vigna unguiculata L. Walp) cultivar BRS-Milênio foi produzida em 2005, pela Empresa Brasileira de Pesquisa Agropecuária (EMBRAPA MEIO NORTE, 2003), Teresina - PI, Brasil.
As sementes foram colhidas manualmente e selecionadas por máquina classificadora de sementes (modelo CS 2000 Grazmec - Brasil) para remoção de sujidades e grãos fora do padrão de qualidade. A porcentagem de aproveitamento em relação ao colhido foi de $95 \%$. A amostra foi moída em moinho de martelos (modelo MML-100 Astecma - Brasil), com peneira interna média (1,0 mm de diâmetro ou tyler 16) e armazenada sob refrigeração a $8{ }^{\circ} \mathrm{C}$ em sacos de polietileno para análises posteriores.

\subsection{Métodos}

\section{Composição centesimal}

As sementes foram analisadas quanto ao conteúdo de umidade, cinzas, lipídios e proteínas $(\mathrm{N} \times 6,25)$, de acordo com metodologia descrita pela AOAC (1990). O teor de fibras alimentares solúvel (FAS) e insolúvel (FAI) foi determinado de acordo com o método enzimático gravimétrico de Prosky et al. (1988). Os carboidratos totais foram determinados por diferença. O valor calórico foi estimado através dos fatores de conversão de ATWATER: $4 \mathrm{kcal} . \mathrm{g}^{-1}$ para proteínas, $4 \mathrm{kcal} . \mathrm{g}^{-1}$ para carboidratos e $9 \mathrm{kcal} . \mathrm{g}^{-1}$ para lipídios (WATT; MERRILL, 1963).

\section{Perfil de aminoácidos}

A técnica foi baseada na hidrólise das proteínas $(25 \mathrm{mg})$ em meio ácido $(10 \mathrm{~mL}$ de $\mathrm{HCl} 6 \mathrm{~N}$, sob vácuo, à temperatura de $110^{\circ} \mathrm{C}$ por 22 horas). Uma alíquota de $25 \mu \mathrm{L}$ foi injetada no analisador Dionex DX 300 para separação dos aminoácidos em coluna de troca iônica e reação pós-coluna com ninidrina. As áreas dos picos obtidos a partir das amostras foram comparadas às da mistura padrão de aminoácidos Pierce (SPACKMAN; STEIN; MOORE, 1958).

Os valores de triptofano foram determinados por espectrofotometria a $590 \mathrm{~nm}$, através de método descrito por Spies (1967), usando-se hidrólise enzimática com pronase a $40{ }^{\circ} \mathrm{C}$ por 24 horas.

\section{Perfil de ácidos graxos}

Os ácidos graxos foram determinados como ésteres metílicos de ácidos graxos por meio de cromatografia gasosa. A farinha de feijão caupi teve seus lipídios extraídos através do método de Bligh e Dyer (1959). Uma alíquota contendo $150 \mathrm{mg}$ de lipídios foi submetida à saponificação com $\mathrm{NaOH}$ 0,5 N em metanol, esterificada com $\mathrm{BF}_{3}$ em metanol (MERCK, Brasil) por meio de aquecimento, e extraída em hexano grau CLAE (Cromatografia Líquida de Alta Eficiência) (MORRISON; SMITH, 1964). A identificação dos ésteres metílicos foi realizada em equipamento Chrompack CP9002 (Middelburg, Holanda). Foi utilizado como padrão o Lipid Standard SIGMA - Fatty acid methyl ester mixtures 47885 para identificação dos picos. As condições cromatográficas foram as seguintes: coluna capilar de sílica fundida CIOLA-WAX, com $20 \mathrm{~m}$ de comprimento e 0,32 $\mathrm{mm}$ de diâmetro interno; gás de arraste: hidrogênio a $2,0 \mathrm{~mL} /$ minuto; injetor splitter a $270{ }^{\circ} \mathrm{C}$, com razão de split de 
1:35; detector FID a $300^{\circ} \mathrm{C}$; e programação da coluna: temperatura inicial de $60^{\circ} \mathrm{C}$, com elevação de $3,5^{\circ} \mathrm{C} / \mathrm{min}$ até $240{ }^{\circ} \mathrm{C}$. $\mathrm{O}$ volume injetado de cada extrato no cromatógrafo a gás foi de $1 \mu \mathrm{L}$.

\section{Conteúdo de minerais}

A amostra (2 g) foi homogeneizada com $20 \mathrm{~mL}$ de uma solução contendo ácido nítrico e ácido perclórico $(5: 1 \mathrm{v} / \mathrm{v})$ e deixada em repouso por 12 horas. A mistura foi aquecida a $80{ }^{\circ} \mathrm{C}$ por 2 horas. Após secagem as amostras digeridas foram diluídas em água destilada e realizadas análises de zinco, manganês, ferro e cálcio, utilizando um espectrômetro de absorção atômica polarizado Zieman AAS Hitachi Z-5000 (AOAC, 1980). O fósforo foi determinado colorimetricamente pelo método de Chen, Tosiba e Warmer (1956), e os minerais potássio e sódio pelo método de fotometria de chama, de acordo com os procedimentos da AOAC (1980).

\section{Atividade inibitória de tripsina}

Para extração dos inibidores de tripsina, um grama de amostra em $50 \mathrm{~mL}$ de $\mathrm{NaOH}$ 0,01 $\mathrm{N}$ foram agitados por 3 horas à temperatura ambiente. A suspensão foi então centrifugada $\left(30.000 \times \mathrm{g} / 30\right.$ minutos a $\left.4{ }^{\circ} \mathrm{C}\right)$ e o sobrenadante foi utilizado para determinação da atividade inibitória de tripsina realizada de acordo com Kakade, Simons e Liener (1969), com algumas modificações (GENOVESE; LAJOLO, 1998), usando-se benzoil-DL-arginina-p-nitroanilida (BAPA) como substrato. A absorbância foi lida a $410 \mathrm{~nm}$, contra os brancos aos quais se adicionou o ácido acético antes do BAPA. Uma unidade de tripsina (UT) foi definida arbitrariamente como o aumento de 0,01 unidades de absorbância a $410 \mathrm{~nm}$ por $10 \mathrm{~mL}$ do meio de reação. Os resultados foram expressos como unidades inibitórias de tripsina (UIT) por grama de proteína e por grama de amostra, sendo uma unidade inibitória responsável pela inibição de uma unidade de tripsina.

\section{Resultados e discussão}

Os resultados de composição centesimal do feijão caupi (Vigna unguiculata L. Walp) encontram-se na Tabela 1 e são comparáveis com outras cultivares de caupi (MAIA et al., 2000; SALGADO et al., 2005; GIAMI, 2005; IQBAL et al., 2006).

Os teores de proteínas estão de acordo com os resultados observados por Maia et al. (2000), Preet e Punia (2000) e Castellón et al. (2003) que obtiveram valores entre 19,5 e 26,1 g. $100 \mathrm{~g}^{-1}$, em diversas cultivares de feijão caupi. As diferenças quantitativas do conteúdo protéico das sementes sugerem que o melhoramento genético induz mudanças neste parâmetro bioquímico (CASTELLÓN et al., 2003).

O conteúdo lipídico obtido neste trabalho foi semelhante ao encontrado por Oluwatosin (1998), 1,5 a 2,0 g.100 g $\mathrm{g}^{-1}$ e por Preet e Punia (2000), 1,8 a 2,0 g.100 g ${ }^{-1}$, sendo esta variação típica das leguminosas (ALMEIDA COSTA et al., 2006). No entanto, outros autores que estudaram o feijão caupi encontraram maiores variações no percentual lipídico $\left(1,2\right.$ a 3,5 g.100 g $\left.\mathrm{g}^{-1}\right)$ (MAIA et al., 2000). Iqbal et al. (2006), por sua vez, obtiveram
Tabela 1. Composição centesimal (g.100 g $\left.\mathrm{g}^{-1}\right)$ e valor energético (kcal.100 $\mathrm{g}^{-1}$ ) de feijão caupi (Vigna unguiculata L. Walp) em base seca.

\begin{tabular}{lr}
\hline Componentes & Feijão caupi \\
\hline Umidade & $6,0 \pm 0,16$ \\
Cinzas & $2,6 \pm 0,05$ \\
Proteínas & $24,5 \pm 0,47$ \\
Lipídios & $2,2 \pm 0,02$ \\
Fibras totais & $19,4 \pm 1,07$ \\
Insolúveis & $16,6 \pm 1,32$ \\
Solúveis & $2,7 \pm 0,56$ \\
Carboidratos & $51,4 \pm 0,63$ \\
Valor energético & $323,4 \pm 0,84$ \\
\hline
\end{tabular}

Valores expressos em média \pm desvio padrão de três determinações independentes.

aproximadamente o dobro do teor lipídico $\left(4,8 \mathrm{~g} .100 \mathrm{~g}^{-1}\right)$ em relação à cultivar analisada no presente estudo.

No que se refere ao conteúdo de fibras, esta cultivar apresentou quantidades de FAS e FAI equivalentes à outra variedade estudada por Salgado et al. (2005), que encontraram 16,4 g.100 g $\mathrm{g}^{-1}$ de FAI e 1,6 g. $100 \mathrm{~g}^{-1}$ de FAS. Observa-se em estudo realizado por Almeida Costa et al. (2006), que os percentuais de FAI e FAS presentes no feijão comum (FAI 19,9 g.100 g $\mathrm{g}^{-1}$ e FAS 2,4 g. $100 \mathrm{~g}^{-1}$ ), na ervilha (FAI 20,3 g.100 g-1 e FAS 1,7 g.100 g-1) e na lentilha (FAI 19,0 g.100 g e FAS 1,4 g.100 g-1) foram próximos aos encontrados neste trabalho. O conteúdo de fibra alimentar total (g.100 g g $^{-1}$ de amostra) analisado por Preet e Punia (2000) em 4 cultivares de feijão caupi marrom foi aproximadamente 4 vezes menor que o encontrado neste trabalho.

Salgado et al. (2005) obtiveram no feijão caupi maduro $29,3 \%$ de fibra alimentar total em relação aos carboidratos totais. Com relação ao aspecto qualitativo, constatou-se que 9,1\% da fibra alimentar total deste feijão é constituída por FAS (SALGADO et al., 2005). Na cultivar BRS-Milênio encontrou-se percentual de $27,4 \%$ do total de carboidratos referente ao conteúdo de fibra alimentar total, e 14,2\% da fibra alimentar total encontrada são representadas pelas solúveis. Estes resultados mostram que o teor de fibras alimentares totais no feijão caupi é elevado, o que poderia implicar na prevenção do risco de doenças crônicas, tais como câncer, doenças cardiovasculares e diabetes mellitus, além de aumentar a absorção de água no cólon, prevenindo a constipação (FAIVRE; BONITHON-KOPP, 1999; FELDHEIM; WISKER, 2000).

A análise de cinzas resultou no valor médio menor que os valores obtidos na literatura (3,2 a 4,8 g.100 g-1) (MAIA et al., 2000; PREET; PUNIA, 2000; IQBAL et al., 2006), estas variações são provavelmente decorrentes da diferença de cultivar e das condições de cultivo.

A composição de aminoácidos do feijão caupi, os requerimentos mínimos estabelecidos para crianças de 2 a 5 anos de idade (FAO/WHO, 1991) e o escore de aminoácidos encontramse na Tabela 2. O feijão caupi, cultivar BRS-Milênio, apresentou cistina e metionina como limitantes para esta faixa etária, enquanto que os demais aminoácidos essenciais atendem às necessidades. Resultados similares foram encontrados por Maia 
et al. (2000) quanto ao perfil de aminoácidos. Em contrapartida, Iqbal et al. (2006) obteve o triptofano como aminoácido limitante, provavelmente decorrente de diferenças metodológicas. É importante destacar que a quantidade de lisina do feijão caupi, assim como nas leguminosas, lentilha, grão de bico e ervilha verde, atendem às recomendações nutricionais de acordo com FAO/WHO (1991), diferentemente do que acontece com os cereais (IQBAL; KHALIL; SHAH, 2003; IQBAL et al., 2006).

A composição dos ácidos graxos do feijão caupi, bem como sua porcentagem de acordo com o grau de saturação, encontram-se na Figura 1a e $1 b$.

O feijão caupi apresentou alto conteúdo de ácidos graxos insaturados (Figura 1b), especialmente de ácido linoléico (C18:2 9, 12-cis). O segundo ácido graxo em maior abundância foi o palmítico (C16:0), outro ácido graxo saturado presente no feijão, muito embora em proporções reduzidas, é o esteárico (C18:0). Os demais ácidos graxos insaturados foram: oléico (C18:1 n6-cis), $\gamma$-linolênico (C18:3 n-6cis) e docosadienóico (C22:2) (Figura 1a).

Em concordância com relatos prévios, o óleo extraído do caupi possui altos níveis de ácidos graxos insaturados (AGI) com variações de 45,8 a 72,9\%, dependentes do genótipo (OLUWATOSIN, 1998). A cultivar BRS-Milênio apresentou a proporção de 70,7\% de AGI, valor obtido por Oluwatosin (1998) com os melhores genótipos para este nutriente. Em estudo de Sinha e Kawatra (2000), os ácidos graxos insaturados linoléico e linolênico foram encontrados em concentrações apreciáveis, variando de 34,2 a $36,8 \%$ e de 13,0 a $23,1 \%$, respectivamente.

Dentre os ácidos graxos saturados observados por Oluwatosin (1998) e Sinha e Kawatra (2000), o palmítico foi o dominante, variando de 20,6 a $38,6 \%$ e de 29,1 a $34,4 \%$, respectivamente, como também ocorre neste estudo. Outro AGS encontrado no caupi, por Sinha e Kawatra (2000), foi o esteárico, com valores de 1,9 a 3,3\%, variação na qual se insere o resultado encontrado na cultivar BRS-Milênio.

Tabela 2. Perfil de aminoácidos do feijão caupi (Vigna unguiculata L. Walp) (g.100 g $\left.{ }^{-1}\right)$, recomendação de aminoácidos essenciais de acordo com a FAO/WHO (1991) e escore de aminoácidos.

\begin{tabular}{lccc}
\hline \multicolumn{1}{c}{ Aminoácido } & $\begin{array}{c}\text { Feijão caupi } \\
\left(\text { g.100 g }{ }^{-1}\right. \\
\text { de proteína })\end{array}$ & $\begin{array}{c}\text { Recomendado } \\
\text { FAO/WHO } \\
(1991)^{*}\end{array}$ & $\begin{array}{c}\text { Escore de } \\
\text { aminoácidos** }^{*}\end{array}$ \\
\hline Arginina & 7,0 & - & - \\
Cistina + metionina & 1,1 & 2,5 & 44 \\
Fenilalanina + tirosina & 7,0 & 6,3 & 111 \\
Histidina & 3,1 & 1,9 & 163 \\
Isoleucina & 4,3 & 2,8 & 154 \\
Leucina & 7,9 & 6,6 & 120 \\
Lisina & 6,8 & 5,8 & 117 \\
Treonina & 4,0 & 3,4 & 118 \\
Triptofano & 4,4 & 1,1 & 400 \\
Valina & 4,9 & 3,5 & 140 \\
Glicina & 4,0 & - & - \\
\hline
\end{tabular}

*Padrão de aminoácidos requerido para crianças de 2 a 5 anos; e ${ }^{* *}$ escore de aminoácidos $=($ aminoácido teste $\times 100) /$ aminoácido de referência.
O teor de minerais de Vigna unguiculata L. Walp, cultivar BRS-Milênio e Vigna unguiculata cylindrica (apresentada na USDA National Nutrient Database) encontram-se na Tabela 3.

A quantidade dos minerais fósforo, ferro e zinco (Tabela 3 ) encontra-se dentro da faixa de variação (302 a $764 \mathrm{mg} .100 \mathrm{~g}^{-1}$; 4 a $12 \mathrm{mg} .100 \mathrm{~g}^{-1}$ e 3 a $8 \mathrm{mg} .100 \mathrm{~g}^{-1}$, respectivamente) obtida por Oluwatosin (1998) em estudo de diferentes genótipos de feijão caupi cultivados em três localizações, entre 1993 e 1994.
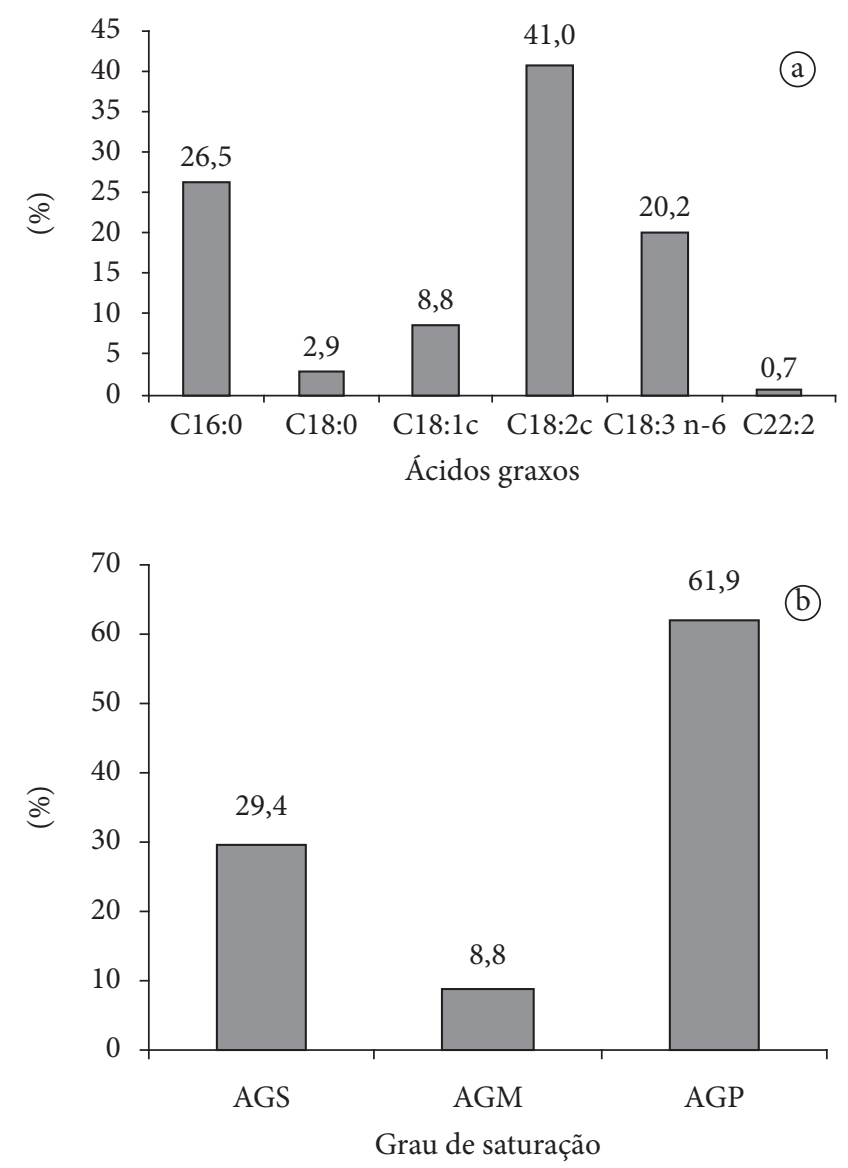

Figura 1. a) conteúdo relativo de ácidos graxos do feijão caupi, cultivar BRS-Milênio; e b) porcentagem de ácidos graxos de acordo com o grau de saturação. AGS: ácidos graxos saturados, AGM: ácido graxo monoinsaturado e AGP: ácidos graxos poliinsaturados.

Tabela 3. Composição de minerais de feijão Vigna unguiculata L. Walp e de Vigna unguiculata cylindrica (mg.100 g ${ }^{-1}$ ).

\begin{tabular}{lcc}
\hline Minerais & $\begin{array}{c}\text { Vigna unguiculata L. Walp } \\
\text { (amostra crua, b.s.) }\end{array}$ & $\begin{array}{c}\text { Vigna unguiculata cylindrica } \\
\text { (amostra crua, b.s.) }\end{array}$ \\
\hline Fósforo & 510,0 & 438,0 \\
Potássio & 1430,0 & 1375,0 \\
Cálcio & 140,0 & 85,0 \\
Ferro & 6,8 & 9,9 \\
Manganês & 1,5 & 1,5 \\
Zinco & 4,1 & 6,1 \\
Sódio & 204,0 & 58,0 \\
\hline
\end{tabular}

*USDA National Nutrient Database for Standard Reference (2006). 
Dentre as leguminosas estudadas por Iqbal et al. (2006), o feijão caupi apresentou as maiores concentrações de potássio (1280 mg.100 $\mathrm{g}^{-1}$ ) e fósforo (303 mg.100 g-1), sendo ainda valores menores que os encontrados no feijão caupi, cultivar BRS-Milênio (Tabela 3). Os valores encontrados por Iqbal et al. (2006) para cálcio (176 mg.100 g $\left.{ }^{-1}\right)$, manganês $\left(1,7 \mathrm{mg} .100 \mathrm{~g}^{-1}\right) \mathrm{e}$ zinco $\left(5,1 \mathrm{mg} .100 \mathrm{~g}^{-1}\right)$ foram próximos aos obtidos neste estudo. Cabrera et al. (2003) encontraram níveis de zinco em diversas leguminosas de 3,3 a 7,0 mg. $100 \mathrm{~g}^{-1}$. A concentração de sódio não é apreciável no feijão caupi (IQBAL et al., 2006).

Moreira-Araújo et al. (2006) encontraram no feijão caupi cultivar BR3-Tracuateua os seguintes resultados do teor de minerais (mg. $100 \mathrm{~g}^{-1}$ ): cálcio - 36,8; fósforo - 437,0; ferro - 4,5 e potássio - 1036,4. O conteúdo de cálcio da cultivar BRS-Milênio é aproximadamente 4 vezes maior que o encontrado na cultivar BR3-Tracuateua, muito embora não represente valor expressivo, diante da recomendação de $1000 \mathrm{mg} /$ dia (NRC, 2001). O teor de ferro foi 1,5 vezes maior na cultivar BRS-Milênio (Tabela 3), quantidade importante diante do fato de que o feijão é a base da dieta de populações de baixa renda, e visto que as fontes de ferro heme são dispendiosas. Ambas as cultivares foram obtidas na Embrapa Meio Norte, cultivadas na mesma região, assim as diferenças podem ser justificadas mais por variações de genótipo do que ambientais. Para os demais micronutrientes os valores mostraram-se equivalentes.

Como se observa, o feijão caupi pode melhorar substancialmente a adequação de certos minerais como ferro e zinco (CRUZ, 2000), principalmente porque estes micronutrientes apresentam funções primordiais por serem componentes do sangue e de enzimas envolvidas na transferência de elétrons, além da síntese de proteína e ácidos nucléicos, do metabolismo de carboidratos, entre outros (KING; SHAMES; WOODHOUSE, 2000; CAIRO et al., 2002).

Terrés et al. (2001) ao determinar as quantidades de zinco presentes em alimentos consumidos na Espanha, observaram que os níveis encontrados em alimentos ricos em proteínas (como leguminosas) eram significativamente maiores que os encontrados em alimentos com baixo teor protéico (frutas e vegetais). Assim, se o melhoramento genético de fato induzir aumento na quantidade de proteínas, pode ocasionar também um aumento nos níveis de zinco presentes no grão.

No que diz respeito ao conteúdo de inibidores de tripsina, a farinha de feijão caupi apresentou 32,5 \pm 0,46 UIT.mg ${ }^{-1}$ de proteína ou 8,0 \pm 0,46 UIT.mg ${ }^{-1}$ de amostra. O valor encontrado na farinha mostra que essa variedade de caupi apresenta menor atividade inibitória de tripsina quando comparado ao valor relatado por Uwaegbute, Iroegbu e Eke (2000) (12,4 UIT.mg ${ }^{-1}$ de amostra ou 49,6 UIT.mg-1 de proteína) e próximo ao encontrado por Rivas-Vegas et al. (2006), sendo este de 7,5 UIT.mg ${ }^{-1}$ de amostra seca ou 31,6 UIT.mg ${ }^{-1}$ de proteína. Este autor considera baixa esta atividade inibitória de tripsina, melhorando o aproveitamento nutricional do feijão caupi.

Marconi, Ruggeri e Carnovale (1997) encontraram em média atividade inibitória de 65 UIT.mg ${ }^{-1}$ de proteína em cultivares silvestres de Vigna unguiculata, valor superior ao encontrado para a variedade analisada. A presença de maior quantidade de inibidores de tripsina nas sementes de caupi silvestres pode ser explicada pela maior necessidade de defesa de suas reservas protéicas (XAVIER-FILHO, 1992). Estes fatores antinutricionais estão amplamente distribuídos nas sementes de leguminosas e cereais consumidos por humanos e, a fim de evitar riscos inerentes ao consumo, recomenda-se aquecimento para inativá-los (LIMA et al., 2004).

O feijão caupi apresenta um elevado potencial nutricional, especialmente para as populações de baixa renda, pelo fato de que no Brasil ainda há ocorrência de casos de desnutrição energético-protéica e carência de diversos micronutrientes, além de risco de 5 a $10 \%$ para déficits ponderais, que aumentam à medida que a renda familiar diminui (IBGE, 2004).

\section{Conclusões}

Este estudo nos permite concluir que o feijão caupi cultivar BRS-Milênio possui atributos desejáveis, como alto conteúdo protéico, energético, de fibras alimentares e de minerais, tais como: ferro, zinco, potássio, fósforo e magnésio. Mesmo verificando atividade de inibidores de tripsina, esta apresenta valor baixo que pode ser reduzido ainda mais pelo tratamento térmico. Constatou-se baixo teor de lipídios, sendo a proporção de ácidos graxos insaturados maior que a de saturados. O perfil de aminoácidos indica uma deficiência apenas de sulfurados.

Investigações bioquímicas em novas cultivares devem ser incentivadas, assim como a busca de grãos que apresentem melhores características nutricionais, como aumento no teor de aminoácidos limitantes e redução de inibidores enzimáticos, visando melhorar a qualidade e o aproveitamento nutricional, além das características agronômicas.

\section{Agradecimentos}

Agradecemos ao Dr. Francisco Rodrigues Freire Filho, à Empresa Brasileira de Pesquisa Agropecuária (EMBRAPA Meio Norte) por ter cedido a amostra e à Fundação de Amparo à Pesquisa do Estado de São Paulo (FAPESP) pela concessão de bolsa de mestrado (Processo 05/52081-8).

\section{Referências bibliográficas}

ALMEIDA COSTA, G. E. et al. Chemical composition, dietary fiber and resistant starch contents of raw and cooked pea, common bean, chickpea and lentil legumes. Food Chemistry, Oxford, v. 94, n. 3, p. 327-330, 2006.

AOAC - Association Official Analytical Chemists. Official Methods of Analysis of the Association of Official Analytical Chemists, 13 ed. Washington, 1980.

Association of Official Analytical Chemists. Official Methods of Analysis of the Association of Official Analytical Chemists. 15 ed., Washington, 1990.

BLIGH, E. G.; DYER, W. J. A rapid method of total lipid extraction and purification. Canadian Journal of Biochemistry and Physiology, Ottawa, v. 37, n. 8, p. 911-917, 1959.

BRESSANI, R. Grain quality of common beans. Food Reviews International, Philadelphia, v. 9, n. 2, p. 237-297, 1993. 
CABRERA, C. et al. Mineral content in legumes and nuts: contribution to the Spanish dietary intake. The Science of the Total Environment, Amsterdan, v. 308, n. 1-3, p. 1-14, 2003.

CAIRO, G. et al. The iron regulatory proteins: targets and modulators of free radical reactions and oxidative damage. Free Radical Biology \& Medicine, San Diego, v. 32, n. 12, p. 1237-1243, 2002.

CARBONARO, M. et al. Perspectives into factors limiting in vivo digestion of legume proteins: antinutritional compounds or storage proteins? Journal of Agricultural and Food Chemistry, Washington, v. 48, n. 3, p. 742-749, 2000.

CASTELLÓN, R. E. R. et al. Composição elementar e caracterização das frações lipídicas de seis cultivares de caupi. Revista Brasileira de Engenharia Agrícola e Ambiental, Campina Grande, v. 7, n. 1, p. 149-153, 2003.

CHEN, O. S.; TORIBARA, T. Y.; WARMER, H. Microdetermination of phosphorus. Analytical Chemistry, Washington, v. 28, n. 11, p. 1756-1759, 1956.

CHRISPEELS, M. J.; RAIKHEL, N. V. Lectins, lectins genes and their role in plant defence. In: VAND DRIESSCHE, E.; KILPATRICK, D.; BOG-HANSEN, T. C. (Eds.). St. Louis: Lectins Reviews, 1991. Cap. 6, p. 183-194.

CRUZ, G. A. D. R. et al. Protein quality and in vivo digestibility of different varieties of bean (Phaseolus vulgaris L.). Brazilian Journal of Food Technology, Campinas, v. 6, n. 2, p. 157-162, 2003.

CRUZ, J. A. A. Dietary habits and nutritional status in adolescents over Europe-Southern Europe. European Journal of Clinical Nutrition, London, v. 54, p. 29-35, 2000. Suplemento 1.

EMBRAPA AMAZÔNIA ORIENTAL. Cultivares de Feijão-caupi BRS-Milênio e BRS-Urubuquara, 2005. Disponível em: <http:// www.cpatu.embrapa.br/novidades_caupi.htm>. Acesso em: 13 abr. 2007.

EMBRAPA MEIO-NORTE. Cultivo de feijão caupi. Jul/2003. Disponível em: <http:/www.cpamn.embrapa.br/pesquisa/graos/ FeijaoCaupi/referencias.htm>. Acesso em: 8 mar. 2007.

FAIVRE, J.; BONITHON-KOPP, C. Diets, fibers, and colon cancer. Advances in Experimental Medicine and Biology, New York, v. 472, p. 199-206, 1999.

FELDHEIM, W.; WISKER, E. Studies on the improvement of dietary fibre intake. Deutsche Lebensmittel-Rundschau, Hamburg, v. 96, n. 9, p. 327-330, 2000.

FOOD AND AGRICULTURE ORGANIZATION/WORLD HEALTH ORGANIZAT-ION (FAO/WHO). Protein quality evaluation. FAO Food and Nutrition paper n. 51, Roma, 1991. 66 p.

GENOVESE, M. I.; LAJOLO, F. M. Atividade inibitória de tripsina em produtos derivados de soja (Glycine max) consumidos no Brasil. Ciência e Tecnologia de Alimentos, Campinas, v. 18, n. 3, p. 309312, Aug/Oct. 1998.

GIAMI, S. Y. Compositional and nutritional properties of selected newly developed lines of cowpea (Vigna unguiculata L.Walp). Journal of Food Composition and Analysis, Oxford, v. 18, n. 7 , p. 665-673, 2005.

IBGE - Instituto Brasileiro de Geografia e Estatística. Levantamento sistemático da produção agrícola. v. 5, n. 12, 1993; v. 6, n. 12, 1994; v. 7, n. 12 , 1995; v. 8, n. 12, 1996; v. 9, n. 12, 1997; v. 10, n. 12 , 1998; v. 11, n. 12, 1999; v. 12, n. 12, 2000; v. 13, n. 12, 2001. Rio de Janeiro: 2001.

Pesquisa de Orçamentos Familiares 2002-2003: análise da disponibilidade domiciliar de alimentos e do estado nutricional no Brasil. Rio de Janeiro, 2004.
IQBAL, A.; KHALIL, I. A.; SHAH, H. Nutritional yield and amino acid profile of rice protein as influenced by nitrogen fertilizer. Sarhad Journal of Agriculture, Peshawar, v. 19, n. 1, p. 127-134, 2003.

IQBAL, A. et al. Nutritional quality of important food legumes. Food Chemistry, Oxford, v. 97, n. 2, p. 331-335, 2006.

KAKADE, M. L.; SIMONS, N.; LIENER, I. E. An evaluation of natural vs synthetic substrates for measuring the antitryptic activity of soybean samples. Cereal Chemistry, St. Paul, v. 46, n. 5, p. 518-526, 1969.

KING, J. C.; SHAMES, D. M.; WOODHOUSE, L. Zinc homeostasis in humans. Journal of Nutrition, Bethesda, v. 130, n. 5, p.1360-1366, 2000. Suplemento.

LALLES, J. P.; JANSMAN, A. J. M. Recent progress in the mode of action and effects of antinutritional factors from legume seeds in non-ruminant farm animals. In: JANSMAN, A. J. M. et al. (Eds.). Recent Advances of Research in Antinutritional Factors in Legume Seeds and Rapeseed. Wageningen: Wageningen Press, 1998. p. 219-232.

LIENER, I. E. Implications of antinutritional components in soybean foods. Critical Reviews in Analytical Chemistry, London, v. 34, n. 1, p. 31-67, 1994.

LIMA, L. M. et al. Comparative digestibility and the inhibition of mammalian digestive enzymes from mature and immature cowpea (Vigna unguiculata (L.) Walp.) seeds. Food Control, Oxford, v. 15, n. 2, p. 107-110, 2004.

MAIA, F. M. M. Composição e caracterização nutricional de três cultivares de Vigna unguiculata (L.) Walp: EPACE-10, Olho de ovelha e IPA-206. Fortaleza, 1996. 87 p. Dissertação (Mestrado em Bioquímica Vegetal), Universidade Federal do Ceará.

MAIA, F. M. M. et al. Proximate composition, amino acid contend and haemagglutinating and trypsin-inhibiting activities of some Brazilian Vigna unguiculata (L.) Walp cultivars. Journal of the Science of Food and Agriculture, London, v. 80, n. 4, p. 453-458, 2000.

MARCONI, E.; RUGGERI, S.; CARNOVALE, E. Chemical evaluation of wild under-exploited Vigna ssp. seed. Food Chemistry, Oxford, v. 59, n. 2, p. 203-212, 1997.

MENCION, J. P.; VAN DER POEL, A. F. B. Process technology and antinutritional factors: principles, adequacy and process optimization. In: VAN DER POEL, A. F. B.; HUISMAN, J.; SAINI, H. S. (Eds.). Recent Advances of Research in Antinutritional Factors in Legume Seeds. Wageningen Pers: Wageningen, 1993, p. $419-434$.

MOREIRA-ARAÚJO, R. S. R. et al. Teor de minerais de produtos elaborados com farinha de feijão-caupi (Vigna unguiculata (L.) Walp.), cultivar tracuateua - 235. In: CONGRESSO NACIONAL DE FEIJÃO CAUPI/6 REUNIÃO NACIONAL DE FEIJÃO CAUPI. 2006, Teresina. Anais... Teresina: Embrapa Meio-Norte, 2006, v. 1. CD-ROOM.

MORRISON, W. R.; SMITH, L. M. Preparation of fatty acid methyl esters and dimethyl acetals from lipids with boron fluoride methanol. Journal of Lipid Research, Bethesda, v. 5, n. 4, p. 600-608, 1964.

NRC (National Academic Press). - Dietary Reference intakes: applications in dietary assessment. Washington DC: National Academic Press, 2001.

OLUWATOSIN, O. B. Genetic and environmental variability in starch, fatty acids and mineral nutrients composition in cowpea (Vigna unguiculata (L.) Walp). Journal of the Science of Food and Agriculture, London, v. 78, n. 1, p. 1-11, 1998. 
ONWULIRI, A. V.; OBU, A. J. Lipids and other constituents of Vigna unguiculata and Phaseolus vulgares grown in northern Nigéria. Food Chemistry, Oxford, v. 78, n. 1, p. 1-7, 2002.

PREET, K.; PUNIA, D. Proximate composition, phitic acid, polyphenols and digestibility (in vitro) of four brown cowpea varieties. International Journal of Food Sciences and Nutrition, Oxford, v. 51, n. 3, p. 189-193, 2000.

PROSKY, L. et al. Determination of insoluble, soluble and total dietary fiber in foods and products: intrelaboratory study. Journal of the Association of Official Analytical Chemists, Gaithersburg, v. 71, n. 5, p. 1017-1023, 1988.

QUIN, F. M. Introduction. In: SING, B. B.; MOHAN RAJ, D. R.; DASHIEL, K. E.; JACKAI, L. E. N. (Ed.). Advances in cowpea research. Ibadan: IITA-JIRCAS, 1997. p. 9-15.

RIVAS-VEGA, M. E. et al. Nutritional value of cowpea (Vigna unguiculata $\mathrm{L}$. Walp) meals as ingredients in diets for Pacific white shrimp (Litopenaeus vannamei Boone). Food Chemistry, Oxford, v. 97, n. 1, p. 41-49, 2006.

SALGADO, S. M. et al. Caracterização físico-química do grânulo do amido do feijão caupi. Ciência e Tecnologia de Alimentos, Campinas, v. 25, n. 3, p. 525-530, 2005.

SINHA, R.; KAWATRA, A. Chemical composition and physicochemical properties of cowpea (Vigna unguiculata (L.) Walp). Journal of Research - Birsa Agricultural University, Ranchi, v. 12, p. $77-80,2000$
SPACKMAN, D. C.; STEIN, W. H.; MOORE, S. Automatic recording apparatus for use in the chromatography of amino acids. Analytical Chemistry, Washington, v. 30, n. 7, p. 1190-1206, 1958.

SPIES, J. R. Determination of trypitophan in protein. Analytical Chemistry, Washington, v. 39, n. 9, p. 1412-1415, 1967.

TERRÉS, C. et al. Zinc levels in foods from southeastern Spain: relationship to daily dietary intake. Food Additives and Contaminants, York, v. 18, n. 8, p. 687-695, 2001.

USDA - National Nutrient Database for Standard Reference, Release 19 (2006). Disponível em: <http://www.nal.usda.gov/fnic/foodcomp/ cgi-bin/list_nut_edit.pl>. Acesso em: 19 mar. 2007.

UWAEGBUTE, A. C.; IROEGBU, C. U.; EKE, O. Chemical and sensory evaluation of germinated cowpeas (Vigna unguiculata) and their products. Food Chemistry, Oxford, v. 68, n. 2, p. 141-146, 2000.

WATT, B.; MERRILL, A. L. Composition of foods: raw, processed, prepared. Washington DC: Consumer and Food Economics Research. Divison/Agricultural Service, 1963. (Agriculture Handbook, 8).

XAVIER-FILHO, J. Sementes e suas defesas contra insetos. Projeto Multinacional de Biotecnologia e Alimentos Bioquímica e Biologia Molecular - controle Biológico de Pragas. Organização dos Estados Americanos - OEA. Imprensa Universitária, Universidade Federal do Ceará, Fortaleza, 1992. 